A Language of Scratches and Stitches: The Graphic Novel between Hyperreading and Author: Katalin Orbán Source:Critical Inquiry, Vol. 40, No. 3, Comics \& Media, edited by Hillary Chute and Patrick Jagoda (Spring 2014), pp. 169-181

DOI: https://doi.org/10.1086/677340

\title{
A Language of Scratches and Stitches: The Graphic Novel between Hyperreading and Print
} Katalin Orbán

In one of the memorable media historical anecdotes of the electronic Stone Age that was the 1970s, security officials learned about haptic reading the hard way when the classified documents hastily shredded before the takeover of the US embassy in Tehran were painstakingly reassembled by hand. The unshredding was not done by intelligence officers but by specially hired local carpet weavers. As the deputy director of the National Security Archive at George Washington University commented, "for a culture that's been tying 400 knots per inch for centuries, it wasn't that much of a challenge." 2 The different time scales of abstract mathematical possibility and human activity are important elements of the unexpected reconstruction, yet the story reveals more than a case of absurdly patient reading. It is also a demonstration of the curious fact that if you cannot read a document with your eyes like an intelligence analyst, you may still be able to read it with your hands like a carpet weaver-a shift that acknowledges reading as a genuinely multisensory experience. The New York Times article mentioning the Tehran unshredding incident (on the occasion of the more recent electronic reassembly of Stasi files) calls the weavers' method "crude," a label both naïve and arrogant in equating predigital slow technologies with a lack of sophistication. ${ }^{3}$ In fact, the role of touch in the embodied reading process can vary in subtle, often unconscious ways, although the significant cognitive consequences of this multisensory experience, which normally go unnoticed, may require cultural confrontations as bizarre as analysts versus weavers to appear.

In the following pages, I will present graphic narrative as a site of reading that merits attention precisely because of the cultural contestation and rival practices it dramatizes in its embodied, multisensory reading process, though in this case we will abandon the different weaving (and unraveling) methods of text and textile for paper and screen. When viewed in a 
broad cultural-historical context, the increasing prominence of graphic narrative in mainstream and even canonical culture-particularly through the invention and development of the graphic novel genre-pinpoints the intersection of two often-related processes. One is the increasing prevalence of hyperreading and hyperattention, and the other is a move away from stable material forms to increasingly volatile and adaptable digital, virtual forms. While these two processes often go hand in hand, there seems to be a tension between the hyperreading encouraged by the multimodality of graphic narrative (its use of different systems of signification) and its enduring reliance on the printed book. Although digital comics (born digital or migrated from print) confirm the broader technocultural trend in which nonlinearity, multitasking, and digital environments are seen as mutually conducive, web comics are just as often a stepping stone to print publication, and plenty of graphic narratives call for a printbased hyperreading without moving to screen reading and surfing. After establishing that this is a significant cultural constellation both in the aesthetic and publishing paradigms, I will examine how two works-Art Spiegelman's In the Shadow of No Towers and David Small's Stitches - utilize this special position to explore a new sense of materiality that belongs neither to a nostalgic dependence on predigital materiality nor to hyperreading in computer environments. ${ }^{4}$

The concept of hyperreading emerged quite recently (1999) in the context of digital literacy and screen-based reading. James Sosnoski links it to the common operations of computer-assisted reading (such as searching and commenting) and emphasizes the constructive aspects of reading from and across texts, singling out behaviors such as keyword filtering, pecking, trespassing, and fragmenting. ${ }^{5}$ Based on subsequent neurological research, Katherine Hayles adds that hyperreading also "stimulates different brain functions than print reading." While she considers hyperreading a healthy response to an information-intensive environment and rejects its criticism as sloppy or dumb reading (basically a deterioration of literacy), she admits that this new kind of literacy impairs the old one (as it "may be involved with changes in brain architecture that makes close reading more difficult to achieve"). ${ }^{6}$ Armando Petrucci observed this in cultural-historical terms as an effect of nonreading practices as early as 1990, stating that (1) reading is no longer the primary form of acculturation, its role in mass culture having been replaced by that of television, and that (2) these differently acculturated people read books with the kind of jumpy, less progressive reading that used to characterize uncultured readers. ${ }^{7}$ The shift is important, however. What Petrucci sees as a contrast between reading and audiovisual environments will appear in Hayles as a split within reading. The set of cultural habits that Petrucci sees (precluding slow, progressive reading for many contemporary readers even in a classically suitable environment for undisturbed individual reading, say a quiet room with a single printed book on the table) become in Hayles's terms "changes in brain function" and "brain architecture." She has some reservations about individual studies that argue for particular ways our brains are being rewired by "a constant state of distraction," pointing to several methodological problems, but she agrees with the larger phenomenon of hyperreading undermining deep attention $(H W$, p. 62). 
While I do not want to equate hyperreading with the reading of comics, the affinities are significant enough to warrant this application. To name just a few of the liberties I am taking with the original concept of hyperreading, the dynamism of reading comics is not database driven (its mixed signs are permanently arranged and cannot be pulled and rearranged through searches); the visible areas and details of comics offer a more homogeneous and continuous "information-intensive environment" for browsing and flexible switching than plural "information streams" to be selected or abandoned (HW, pp. 61, 69). At the same time, even linear graphic narratives involve a fundamentally divided attention. A linear narrative of uniformly-sized panels in a conventional reading order- a reductive use of the medium's complex possibilities — would still involve different levels of overview, the reader's attention moving sequentially as well as in and out of local details, dealing with images embedded in other images and with visual information connected to words and contained within the graphic lettering itself. The seemingly uniform panels may, in fact, show important variations in their verbal content (dialog-driven or silent panels; words connected to another panel). The identity of discrete components and possible links between them are not trivial either even in such a straightforward panel arrangement, let alone in sophisticated constructions of narrative and page layout; the components' narrative, temporal, spatial, verbal, and visual connections almost never coincide in a single mandatory path and rather compete as alternatives. This does not fully equate the state of distraction associated with hyperattention, as I will show later in the discussion of Spiegelman's and Small's books, but it is a type of dynamic multitasking akin to and supported by browsing habits. Given this, graphic narrative should flourish in the digital "native habitat" of hyperreading, and one might not expect substantial hurdles or major alterations in the transition process. However, the seemingly perverse alliance of hyperreading and paper in graphic narratives is not a random contingency and, for that reason, not so easily jettisoned.

Graphic narrative's potential investment in the medium of print is, of course, inseparable from the embattled cultural prestige of comics, a subject exhaustively covered in comics scholarship. ${ }^{8}$ The graphic novel in particular has emerged as a product of the gentrification of comics into a canonizable literary form over the last twenty years, moving selected long-form comics from a literacy discourse to a literary one. In this move the category of literature and the format of the codex book mutually imply and confirm each other, allowing graphic narrative to appear as a book both on the market and in reception, being distributed in book stores and reviewed in nonspecialized publications, ${ }^{9}$ while infusing the literary with the kind of multimedial and nonlinear forms and reading habits that are central to the profound contemporary transformation of the book and the "new brains" of its readers. If, as Thierry Groensteen argues, the dominance of multimedial visual culture is reversing the wordimage hierarchy rooted in the logocentrism of alphabetic cultures and (see "W," p. 36), as Jay Bolter suggests, we live in an environment of reverse ekphrasis (words described by pictures), graphic narratives can perhaps hook the native inhabitants of that world. A recent collection 
on "how librarians learned to love the graphic novel" makes several references to this capacity of the genre and always against the backdrop of the dominance of electronic culture: "in a world that is going more and more with digital content, graphic novels are one of the last varieties of the printed form that are gaining in popularity as each year goes by"; 10 "at a time when most academic libraries are busy responding to the electronic research needs of their patrons, comics and graphic novels are a resilient reminder of print culture." ${ }_{11}$ By contrast, in the PR invention of the graphic novel as "the new novel" in the late 1980s and early 1990s, the alleged novelty was often located in postwriting and postprint culture: "heralds of a new era in visual literacy" and "literature for the post-literate generation." 12 For one thing, this prediction seems to have underestimated the time lag between technological advancement and a more conservative transfer of cultural prestige trailing behind it. This lag and the special stakes of elite sanctions for graphic narratives may partly explain why the medium, while thoroughly embedded in a multimodal reading culture, is not less but more attached to paper and print than purely textual books in more pedigreed genres.

Secondly, while the remediation of comics for digital platforms offers numerous benefits of "true" hyperreading, such as interactivity or dynamic animation, it also seems to alter profoundly the alliance of sequential exploration and visuo-haptic processing that has become a specific modality of processing graphic narrative. Roger Sabin gave some early insight into the obstacles to a successful transfer of comics to the web, seen by many as the solution of the-primarily economic-disaster in the comics industry. Writing in 2000, he enumerates several economic, technical, and aesthetic factors: for instance, the limitations of web and computer access may not match the portability and affordability of print comics, and the reading of web comics is less immediate due to downloading and screen size. ${ }^{13}$ Many of Sabin's objections are obsolete today (especially the technical ones solved by cheap web payment systems, fast downloads, portable devices, eye-friendly e-paper, and more affordable access to internet services). The concerns in this over-ten-year-old study that seem most intact are the different topographies of page and screen and the tactile, sensual qualities of creating and reading comics predigitally.

[Comics] can be bent, rolled-up, roughly opened or whatever. They can be held in different ways: cradled in your hand or gripped at the edges. We know how far into a comic we've read because we can feel how many pages are left. There are also smells: of dust, glue and paper. Compared to this very sensual experience, clicking a mouse just isn't the same. This question of tactility is magnified when it comes to actually creating comics. ${ }^{14}$

Interestingly, of the spatial and sensual aspects of comics extolled in these elegiac comments, spatial ones are turning out to be the more robust obstacle to remediating the specific haptic modality of print comics for the screen. Questions of prestige aside, the importance of the haptic modalities of reading graphic narrative in print are confirmed by 
neuroscience research, where it has been established that visuo-haptic processing is especially suited to sequential spatial exploration. Experiments on children's reading acquisition, for example, have shown the involvement of the haptic modality to have measurable effects on memory and association ${ }^{15}$ and to be more analytical and less global than purely visual perception. ${ }^{16}$ If this is the case, the reading of the graphic novel suffers more-even at the level of cognitive processing - from a sense of relative haptic deprivation than other kinds of narratives.

It is hard to judge the relative importance of cultural legitimacy and haptic investment in graphic narrative's attachment to print despite its kinship with hyperreading. Still, a significant change in the haptic experience of reading electronically - through a combination of technological development and a naturalization of new interfaces - is most likely a precondition for the continued replacement of printed graphic narratives by digital publication forms. A key area of development in touch screen technology, ${ }^{17}$ such advanced haptic interfaces have the capacity to diminish the difference between the print text experienced as permanently integrated with its material base and the digital text experienced as "ontologically intangible and detached from the physical and mechanical dimension of [its] material support"18 (a rapidly evolving range of fixed and portable devices). Haptic response-a buzzword, if there has ever been one-can thus contribute to a specific materiality of digital graphic narrative that sustains a meaningful tactile connection to the text. Yet, such pulses and vibrations may reach the reader within a very different spatial experience, for the effects of a screen interface on the panel layout of the page can profoundly alter the possibility of spatial exploration itself, for example by removing off-screen elements from physically experienced space. ${ }^{19}$ The alternation and parallel processing of verbal and visual components through different levels of overview and detail, which characterize even linear graphic narratives, may be remediated through multiple windows and various magnification tools, 20 but incomplete pages or even panel-by-panel viewing can become the dominant reading mode in the interest of "Onscreen legibility" (especially on smaller devices). ${ }^{21}$ Besides affecting the digital migration of comics with a preexisting page layout (where legibility vies with the rival priority of archival or aesthetic fidelity), ${ }^{22}$ this also informs the remediation of comics topography across multiple platforms.

Therefore graphic narrative is hardly confined to print today, and extensive experimentation with print and digital formats and distribution can be expected to continue along with migration in both directions. Yet, it is the print-based graphic narrative integrated with the form of the codex book that uniquely encapsulates the larger cultural transition dispersed in the platforms, formats, modes of reading, and models of distribution characteristic of convergence culture. (How firmly the medium-specific sense of reading comics is still tied to print is shown when even a digital comics publisher praises the ability of his application to handle page layouts as coming "closest to emulating how we read comics," tout court. ${ }^{23}$ While the combination of multimodality with a renewed emphasis on materiality 
is relevant to the medium as a whole, I will offer a detailed analysis of two works that reflect on this connection more acutely. Rather than typifying the diverse works within the medium, Spiegelman and Small illustrate what makes graphic narrative a culturally significant medium at this time. In the Shadow of No Towers and Stitches, both written over the past decade, make distinct use of the material qualities of print media in their multimodal reading space as part of a larger project of reaffirming embodied experience.

\section{Touch Wood-Embodied Perception and the Materiality of Print in In the Shadow of No Towers and Stitches}

In the Shadow of No Towers, Spiegelman's creative response to 11 September and its aftermath, illustrates a strong version of the argument, as the reconstructed diary of the author's personal experiences takes both hyperreading and bookness to extremes. It encloses a topologically fragmented, dynamic-figuratively exploding-reading space in an emphatically material superbook. While the breaking up of the reading space responds to the event, the tactile visuality of the object intervenes in the networked imaging of $9 / 11$ as a televisual spectacle that threatened to supplant physical, local presence as a primary experience of the event. ${ }^{24}$ The inescapable materiality of In the Shadow of No Towers weighs on the reader from the start (it weighs in at one pound twelve ounces, in fact). Its thick cardboard and large format push the material quality of the book into the sphere of recognition and, to a great extent, materially counteract the structural effects of its original serial publication. The book is, in fact, a complex exercise in salvaging and consolidating fragile and perishable serial formats into a permanent object: a cardboard monument perhaps not more lasting than bronze, but lasting enough. It not only assembles its own immediate antecedents- the prior serial publication in Die Zeit and other periodicals_-but also incorporates a longer prehistory by other creators in a comic supplement section nearly equal to Spiegelman's own. This move-which reflects both the common life cycle of graphic narrative from comic book to trade paperback and its longer evolution into increasingly prestigious and permanent formsgives additional emphasis to the historical embeddedness of material objects accumulated and transformed over time and bearing the marks of time's passage, making each object (even originally identical copies) unique. ${ }^{25}$

The text as material object is also emphasized through the tactile layering of its surface, achieved through variations of surface that gesture towards the artist's book, yet are more distinct, articulated, and deliberate than the effects of rich physicality and material variation of surface resulting from traditional printmaking technologies. On the covers and spine that frame the book, the alternation of glossy and matte areas calls attention to the physical superimposition of certain images and letters on others. The less detail these glossy shapes contain (the black-on-black towers and cartoon characters), the more striking their reflective 
quality, which optically highlights the surface (you can literally see yourself in the mirror of these images) yet confirms the materiality of this surface as part of a textured object in a tactile way. Where the physically existing three-dimensional object brushes against its environment, this layering also changes as the history of use gets written on the covers in a language of smudges and scratches. Layering is more illusory inside, where different drawing and painting techniques and tonal scales are juxtaposed and often overlap, and it is only the thickness of the cardboard that materially sustains the illusion of tactile depth. (This diversity of techniques includes computer-generated images, but the book object brings these back to the emphatic material of paper no less than the images drawn or painted with more traditional techniques.) The sense of materiality is thus established primarily through a tactile relationship, in which hand-book contact and haptic visuality mutually inform each other. Aloïs Riegl described haptic visuality as a seeing from proximity that was literally displaced by the large cultural shift to a privileged optical distant view (Fernsicht) due to the parallel rise of figurative space and decreasing physical tactility in visual and decorative art. The book object of In The Shadow of No Towers consistently reinforces an interest in the material and tactile-restoring a haptic sense of three-dimensional space to the abstract two-dimensional flat plane through perceptions and "memories of tactile experience," 26 occasionally bolstering this by identifying panels and pages with three-dimensional architectural objects, particularly the twin towers themselves (in the rotating panels that literally turn into a view of the towers or the stretching of page height to match the tall building represented [fig. 1]). This is part of a broader affirmation of closeness and locality (of the "rooted' cosmopolitan" Spiegelman discovers himself to be) that relies on and gives access to the close senses of touch, taste, and smell-a richness of the nontelevisual human sensorium that is, in literal physical terms, compressed into the tactile qualities of the book ( $I, \mathrm{p}$. [i]). This is clearly a reaction to the electronic, networked imaging of 11 September-exemplified in the televisual fascination of infinite replay on $\mathrm{CNN}$ (see $I$, pp. 1,2,8)-or, more precisely, to the conditions that made 9/11 a disaster crafted for a world of hyperattention. It is not a simple rejection, however, but rather a difficult renegotiation of the status of experience in convergence culture, in which the validation of real materiality through the demystification of unreal images misses the point of the "changing dynamics of embodiment and perception." As Laura Tanner adds in her corrective to dismissive assessments of Ground Zero pilgrimages and the public's allegedly naïve desire for contact: "Caught up in the experiential dynamics of changing forms of embodiment not yet fully understood or articulated, the public often insisted on seeking the referent of affect at the intersection of the 'natural' body and the stable object world." ${ }^{27}$ Given the shock and devastation of the attacks, the scale of this insistence was exceptional, but the difficulty of correctly responding to the experience of the event was rather exemplary of the troubled status of real contact and experience more generally.

The zone of proximity that In The Shadow of No Towers valorizes through its haptic visuality is no less important for Small's memoir of a disturbing and terrifying childhood- 
one plagued by silence, emotional distance, illness, and disability-but Stitches inhabits this zone differently. Instead of foregrounding embodied experience through the materiality of the multimodal text engaging our bodies, it foregrounds the vulnerable material body with its epidermal surface and intricate layering as it takes shape in the book object. Whereas Spiegelman invites us to hold his book and close the distance of idealized optical vision by approaching the multimodal text bodily, Small invites us close to the book as an imperfect body; where Spiegelman insists on our embodied experience of reading as an approximation and trace of his effort to reenvision a reality evaporating in a thoroughly mediatized spectacle, Small creates a material form that bears witness to his embodied experience in the body of his book. Spiegelman's is a historical challenge taken personally: to reorient the reader from the "awesome" sublime of 9/11 to a more contingent history that does not transcend material bodies and traces (I, p. 1); Small's is a publicly relevant personal challenge: how not to relinquish his loss of voice to a metaphorical interpretation, a set of culturally ascribed meanings based on abstracting truth, subjectivity, and disability from embodied experience.

Stitches is a mostly chronological though lacunar account of Small's childhood and early youth in Detroit from age six to thirty. The main narrative thread follows protagonist David's successive illnesses while also incorporating various episodes of family prehistory. In a difficult, disturbed family of many secrets and as many styles of dysfunctional communication (say, the language of cupboard slamming), David identifies the language of symptoms as his own: "getting sick, that was my language" ( $S$, p. 19). The key event in this story of symptoms is the throat cancer David develops as a result of his radiologist father's X-ray treatment of his sinus problems and the nearly complete loss of voice he suffers as a result of his throat operation (possibly because his frugal parents postpone the operation for years).

Both this narrative and its representation revolve around the relationship between the epidermal surface and the interiority inherent in the three-dimensional space of the body, a relationship introduced in the book's opening pages. A three-panel epigraph simultaneously embraces and questions paper as a surface. It shows a child magically diving through a blank sheet of paper laid out for drawing, leaving behind three unused crayons scattered in a corner of the sheet (fig. 2). By rupturing the plane and partially disappearing through it, the character we soon come to identify as David reveals the liberty that depthless graphic media has on the constraints of space that usually rules physical bodies. At this point, the character's and the creative artist's clever trick appears as a self-reflexive visual wordplay or a sight gag, based on a "double sense" of visual language in comics and animation that depends on the material identity of a visual element in its autonomous and referential functions. ${ }^{28}$ Each of the three outlined blank sheets (penetrated by the diving boy) is materially identical with the blank sheet of the frontispiece of the physical book. The blank page is simultaneously the surface of representation and its referent, the joke working in the oscillation between the truth of the fantastic reality referenced by the lines and the truth of the surface marks (lines) themselves as the only reality. This involves two degrees of an imaginary flattening of space. The threedimensional imaginary space of the drawing-emphasized through light and shadow and 
corresponding to the character's movement-collapses into the flatness of the page; the real space-occupied by the book object held by a corporal reader-collapses into an abstract plane subject to a mute and disembodied act of reading. When first encountered, these panels are simply a playful invitation to dive into the still-unseen world of the book awaiting one behind the title page. Their fuller meaning only emerges later in a richly detailed narrative context (see $S$, pp. 56-63), when the visual trick turns out to herald the book's engagement with both the page as plane and material object and the body as surface and interiority, both subject to breaks fantastic and real.

The body first appears as an enclosed and embattled space of interiority vulnerable to an intrusive, normative outside that is institutionalized as a care for the body. This negotiation between inside and outside also involves the question of meaning: how is one's subjectivity connected to what can be read from the body (whether directly on the surface or from its depth)? The body's surface is registered in the hostile world of shots and enemas in the narrative, while its depth emerges through speaking wounds, inaudible shouts, and subjective travels into the body's interior. The moment David is born, his body fails to meet a preexisting standard, a failure that propels the entire narrative. "I was born anxious and angry. My sinuses and digestive system didn't work as they should have” ( $S$, p. 20$)$. This body is introduced as disabled — diverging from a normative standard understood not as a fantasy but a functioning reality of the complete and self-sustaining human subject. Symptoms indicate interior malfunctions that challenge medicine with the difficulty of direct perception and access, a challenge met with a host of violent intrusions and dislocations of the body (shots, enemas, cracking the neck, and X-rays) to bring it back to normal and to facilitate a better flow between its inside and outside (see $S$, pp. 20-21).

These early panels present the body-both verbally and visually-in terms of its vulnerable, discontinuous surface (its orifices ever anxiously awaiting the next medicine-filled spoon or enema tube), as a negotiation at a permeable epidermal borderline about what is properly inside and outside. (Stitches will also build up the materiality of the paper-based multimodal textual object out of this body, but far more gradually than Spiegelman's invitation to haptic visuality.) The litany of low-tech manipulations and violations of the permeable body (including later examples of suicide by drinking Drano, the nails of crucifixion, burning hands with scalding water, and others) are juxtaposed with a more magical, futuristic medical technology of visualization, the x-ray as wonder vision and cure (see $S$, pp. 73, 87, 93). "Piercing the unknown with radiology" proclaims an ad featuring an army of doctors "marching bravely into the bright and shining future" ( $S$, p. 27). This mode of visualizing the interior points towards the nascent "'nanopolitics" of difference, which, as Paul Gilroy explains, "not only departs from the scalar assumptions associated with anatomical difference but accelerates vertiginous, inward movement towards the explanatory power of ever-smaller scopic regimes." ${ }_{29}$ Yet, under the spell of the unseen and unseeable, this seemingly less violent, enhanced vision of the invisible interior turns out to be the most aggressive, even lethal of 
them all. This is implied, well ahead of any revelation of the actual damage, by the dramatic contrast between David's fragmented, disjointed experience of the X-raying process and the machine's view of him (see $S$, pp. 22-23). Unlike the patient, his X-ray portrait smiles, bringing a better, "cured" David to the surface-if not to his own skin, at least to that of film as a sensitive substitute. The same structure of decomposition will return, as if to finally confirm the initial intimation of destruction, in the scene of the father's confession (though no apology) many years later (see $S$, pp. 289-91). This quietly lethal ambition of a penetrating vision is also echoed in the ubiquitous prosthesis of spectacles. The hostility of these technologies of enhanced visualization - in league with medical efforts to disclose the secrets and mysteries of the body - is visualized in the appearance of spectacles as eyeless blank lenses signaling a cruel or at least impenetrably incomprehensible human being who intentionally, mindlessly, or unwittingly mistreats the child protagonist in his or her care (fig. 3). ${ }^{30}$

When the visual epigraph returns in a full narrative context, it integrates these bodily concerns with questions of the material book as a created world, as the sheet of paper is mapped onto the body's epidermal boundary (see $S$, p. 62). David's flight through this paper/skin is driven by parallel violations of inside and outside in body and on paper. David and his brother like "seeing the x-rays of little kids' stomachs" and the odd objects they swallowed ( $S$, p. 28). As a counterpoint to what's improperly inside, David encounters the opposite during a prohibited exploration of the hospital: a lab full of malformed fetuses in jars, improperly outside, especially when one of them even climbs out and chases him down the corridor. This chase in a mysterious cavernous building soon recurs in a dream space and is identified as a body's interior, namely an esophagus leading to a stomach. When David dives through the paper, the hole he falls into is both the space of two-dimensional cartoon creatures (freed from their plight with the help of a pencil or an eraser) and the inside of the human body (while also referencing the rabbit hole of Alice's Adventures in Wonderland, part of an Alice theme running through the book). The inside to which he withdraws from a hostile external world (now a mob of neighborhood children instead of the hostile fetus) is populated by cartoon creatures who come alive and scamper off the pages (see $S$, pp. 45, 48-49).

All this attention to the paper-based nature of the printed book object could in principle come across as a withdrawal, a return from new-fangled technological systems mediating the reality of a "true" and "natural" sensory world. Such a return would correspond to the position of Luddite "naïve realists" in Michael Heim's classification of techno-pessimists and optimists:

Many naïve realists take reality to be that which can be immediately experienced, and they align computer systems with the corporate polluters who dump on the terrain of unmediated experience... The suppression [of reality] comes through 'the media,' which are seen to function as vast, hegemonic corporate structures that systematically collect, edit, and broadcast packaged experience. ${ }^{31}$ 
Adopting some version of this naïve (and nostalgic) realist position would not only valorize traditional materiality and embodied experience but would primarily serve to provide a privileged position based on some notion of idealized unmediated experience. (This privilege would be closely associated in our case with the cultural prestige of the traditional book form as the proper repository of literary value.) This, however, is curbed by the hyperreading potential of the graphic narrative, in which the simultaneous break through paper and body boundaries entails a signifying surface of breaks, rips, holes, and stitches-the multimodal construction and reading of the graphic novel.

\section{Hyperreading and the Multimodal Text}

Spiegelman's book foregrounds this hyperreading potential excessively and explosively, as if testing the limits of the medium already experimentally stretched by its oversize materiality. Yet, these excesses only accentuate tensions of multimodal print reading that are quietly naturalized in more conventional linearly structured narrative comics. In the Shadow of No Towers plays up its multimodality with its verbal-visual signs, emphatically heterogeneous visual codes, and the formal fragmentation within its large frames. The expanded reading space of the large and relatively few pages offer conditions for the reader's attention that are closer to searching and browsing than to a predominantly linear reading/viewing process. The reader's attention is divided not simply between verbal and visual information but between the competing mininarratives of the page, each with its own form, space, and style (panel size, border type, color palette, and more). In the Shadow of No Towers privileges an intense multisequentiality, combining both the sequential character of comics and the nonsequential or multilinear character of hypertext. In most pages, there is no obvious order in which the narrative develops. Rather, the differences in style and technique invite one to read hypertextually, alternating immersion in a subset of closely connected elements with following links between them.

The first page consists of seven such subunits — the single-panel title and six multipanel strips (with two to twelve panels)—floating between homogenous white gutters. The variation of horizontal and vertical orientation between the multipanel strips precludes the perception of an imaginary narrative ribbon segmented into strips and panels from the start. Groensteen suggests that the strip can be a contingent entity somewhat randomly determined by the publishing format or an aesthetic-narrative unit with its own role in the "apparatus of enunciation." 32 In the former case, the cartoonist proceeds in a predetermined (mostly conventional) direction of reading, bumps into the edge of the page, and moves to the next line. This resembles the line-by-line presentation of any linear text, which is commonly considered an external visual accident attributed a low (or zero) level of significance in 
narrative prose. Groensteen argues, however, that the pause is longer and more significant in comics because the eye dropping and returning to the beginning of the next line typically travels longer relative to the page size. In the latter case, the reading process relies less on the "regularity of a rhythmic reading," and the strip appears a less neutral and transparent integrated element of the layout. Groensteen discusses both of these alternatives as different ways to manipulate progression, acceleration, and duration in narrative development proceeding along a route.

Spiegelman's use of self-contained and linked strips and panels has a different logic, however. The centrifugal and centripetal forces within each strip and between the strips are more immediately and powerfully present in representation than any segmented route. In fact, this centrifugal-centripetal force field on the level of the strip is the primary structuring principle of the page. The multipanel strips are cohesive reading/viewing units because of their immediately apparent internal visual uniformity within a space of juxtaposed differences, which is confirmed by the internal narrative cohesion of their miniplots upon immersion into the strip. Yet each of these self-contained strips has at least one element on the verge of detaching itself as if expelled or trying to escape. The American flag in the fourth panel of the strip showing a family watching television, the ad for Jihad footwear, the shoe dropping in the corner of the "Etymological Vaudeville" strip, and the lettering of the title panel all display this centripetal force of uncoupling, at times minimally by just a subtle change of border style responding to the impact of colliding objects in the panel (a tiny airplane hitting Art's television set) and at times more dynamically rotating and moving away (a partial image of the glowing tower about to collapse [fig. 4]). The juxtaposition and partial overlap of the strips within the page create implicit links between them, which can be actualized by numerous reading sequences in a nonhierarchical space open to repeated recentering. It is the moving parts of each strip that add more explicit links to these, propelling the viewer's gaze outward to the gutter or to a neighboring node or lexia (to borrow a term from hypertext theory).

Of course, this multicentered, multilinear, linked dynamic space corresponds to the reality of explosion, fragmentation, and dissolution entailed in the terrorist attack, which extends beyond its literal representation into a topology of disaster. (This is also a topology of the aftermath; the reading paths correspond to traversing the transformed landscape of the neighborhood, the text's privileged level of public space in the face of the national discourse of the war on terror.) At the same time, the comic sustains a peculiar temporality on the level of the page that is both fragmented (into interrupted narrative kernels) and contemplative (a contemplative reflection on interruption and fragmentation). In the page in question, these contradictory aspects of time and attention are literalized in the instant (the attack conceived as instantaneous rather than processual) and in the interminable duration between instants (the new time defined by the possibility and therefore a possible repetition of the attack-a comicsstyle literalization of waiting for the other shoe to drop).

In the double-page tableau as a whole, the self-enclosed terrain encourages prolonged browsing rather than a narrative impetus that would drive a turn to the next page. (This is, in 
fact, key to the often-disappointing limits of historical interpretation in the book, as the counternarrative element of Spiegelman's authorial strategy precludes situating 11 September in a historical narrative interpretation deemed more valid than the rejected spectacle of instant history and the official discourse of the war on terror.) The contemplative effects of this selfcontained commotion may recall the decorative principle of the kind of tableau that overwhelms narrative sequence insofar as they invite a lingering perusal of the pages as a kind of tapestry, ${ }^{33}$ but the resemblance ends with the dominance of the tableau as a self-sufficient space with its own contemplative time. Spiegelman's subpanels demand primarily rhetorical reading, and it is the reduction of narrative development and the multiplicity of competing narrative kernels that allow these rhetorically structured parts to take on a more contemplative character by exploration through browsing and return (rereading, reviewing, and rerouting). So the possibility of contemplation is based on a negative principle of arrested development and relative containment in the tableau rather than a positive decorative principle overriding the rhetorical logic in reading comics. Still, the element of return in such an exploratory browsing within the topography of the page is an alternative to repetition as instant replay.

Within the visual style of Small's book, the most characteristic device in the signifying multimodal surface of breaks and stitches is the consistent mismatch between outline and fill in the grey-toned world of pen-and-ink drawings combined with watercolor. Since the fill is often erratically incomplete (rather than overflowing), the images are constructed out of visual gaps and overlays within the panels with an effect varying between sketchy tentativeness and expressive emphasis on detail. In the multimodal graphic novel, this gap-ridden display of near correspondence can occur on various levels: in the elevated importance of the gutter and in between verbal and visual signs (often out of sync for long pages of withheld verbal information). If the visual epigraph of the diving boy signaled the surface/interiority and body/paper concerns of the book, the paratextual detail of white lettering on solid black chapter title pages signals the need to read the blanks together with the positively marked surface and to locate meaning in the interdependence of gaps and the surface they break up. This is especially prominent in the frequent representation of experience through juxtaposed discontinuous details from a child's uncomprehending perspective, above all the confused, disintegrated experience of medical procedures (see $S$, pp. 180-82, 192) (fig. 5).

On the level of word and image, the discrepancy of outline and fill that creates gaps in the self-identity of anything represented corresponds to the insufficiency of verbal knowledge for comprehending and articulating experience. The lack of (verbal) knowledge about the body haunts the memoir-both in a range of childhood terrors and in the concealment of the illness and its consequences from David. The secret is brought to light by yet another transgressive act of visualization - David opening his mother's writing desk with a forgotten key and finding (instead of a fetus in a jar) an unfinished letter: "Of course the boy does not know it was cancer" (S, pp. 202-6). When he utters the word in a scene of confrontation in the "rasping whisper" that is his literally and materially impaired voice (rendered in the visual notation of 
dotted speech balloons), his father responds: "Well, the fact is, you did have cancer . . But you didn't need to know anything then ... And you don't need to know about it now. That's final!" ( $S$, p. 238). This violent separation of fact from knowing through the denial of words locks David in his experience and in his body represented in his sensation of "living inside [his] own mouth," a closed echo chamber for his own words, as he sits with mouth closed, eyes shut, and ears covered. A four-panel double page shows him sitting on the couch in the living room, while also sitting on his own tongue in the "hot, moist cavern" of his mouth surrounded by a double line of his giant teeth—an internal living room $(S$, pp. 216, 217).

David's recovery (both from his illness and his family) is therefore a struggle for selfpossession through the comprehension and articulation of embodied experience. In this struggle, experience and its articulation are on a continuum; experience is not posited as something naturally unmediated and fully possessed unlike verbal knowledge withheld by the adult world. In a number of scenes, such as David undergoing and waking from anesthesia, smudges and blurry outlines indicate an unclear sense of experience (see $S$, pp. 180-82, 192). The struggle does not lead to a restoration of a single, unique, continuous, and self-identical body (such has never been presumed to exist) but rather a stitching together of the wound between subjective interiority and the world outside the sheltering-confining asylum of the self, connecting the tissues of body and world.

This is where the embodied interaction between book and reader and-through the proxy of interior architectures of the body intimated within the flat surface of paper-between author and reader come into play (fig. 6). Embodied subjectivity is frequently figured in the book as an interior space, often represented as a body cavity or as an architectural interior and less frequently as an interior landscape (see $S$, pp. 257-68). Given the reality of pain and damage in the narrative, such interiors could be spaces of withdrawal negatively defined as a lack of interchange with the outside world, yet they are also narrated as uncharted interiorities to be positively discovered. These spaces are at times small and thunderously loud (as in the echo chamber for the words in David's brain, when he is "living inside [his] own mouth"). At other times, they are grand and monumentally silent as in David's recurring dream that takes him through secret narrow passageways to the "temple whose guts had been bombed," the abandoned, ruined temple that is his embodied self ( $S$, p. 242 and see pp. 216, 217-23, 24042). In either version, however, they are spaces that figure the body as a chamber of internal experience without outward expression (that results in amplification or silence inside). This raises the stakes for the book as communication between author and reader.

Through a variety of connections between body and paper surface and between body and book depth, Stitches succeeds in building a complex relationship between the book and the site of embodied experience, whereby the material object encountered by the reader comes to stand for the body without reducing that body to metaphor (for example, pushing for a metaphorical understanding of voicelessness). Following David Mitchell and Sharon Snyder's critical analysis of disability as a frequent "opportunistic metaphorical device" in literature that serves to embody textual abstractions (the materiality of metaphor manifested in the 
representation of the disabled body), ${ }^{34}$ a review of Stitches raises questions about the invitation to read David's silence in such a metaphorical way. ${ }^{35}$ On such a reading his voicelessness (along with the chain of physical interventions that have led to it) literalizes a preexisting metaphorical silence, and metaphor attains materiality in the protagonist's physical impairment. Since both the metaphorical and literal senses of disability operate in the book simultaneously, the reviewer acknowledges that its metaphors do not prevent the book from engaging with disability as, what Mitchell and Snyder call, a lived "experience of social or political dimensions." ${ }^{36}$

I would like to suggest a different kind of figuration at work here. The articulated, structured flat surface of the printed page is construed not as an abstraction of embodiment (subsuming and textualizing the reality of experience) but rather as an access point through which the interiority of the ruined temple can (and must) be reached. The book materially held by the embodied reader is thus a crucial element in a chain of mediated materialities. This chain is one of multiple mediated reembodiments of experience that has a metonymic rather than metaphorical logic. From drawing as a kind of handwriting to the reader's holding of the book, a chain of contiguities both discursive and physical connect the two. Rather than abstracting both the writing and reading subject into disembodied functions of the text (the corresponding muteness of the acculturated reader of literature permitted to access the textual world through her or his eyes alone), the metonymic chain adds a material dimension to the autobiographical pact by embracing the world of sensory experience and obligating the reader to imaginatively enter that realm on the far side-the authorial side-of its textual representation.

Although I suggested earlier that Spiegelman insists on our embodied experience of reading as an approximation and trace of his effort to reenvision a reality evaporating in a mediatized spectacle, and Small creates a material form that bears witness to his embodied experience in the body of his book, the two cases are ultimately not as different as they seem. When our haptic seeing is encouraged by the intensification of the material object quality of the big book, this mirrors Spiegelman's (and protagonist Art's) own effort to protect and reclaim his embodied experience both from the shattering power of a personally witnessed catastrophic event and from the audiovisual spectacle that supplants it as a primary form of witnessing 9/11. And in Stitches, where the main narrative and representational focus is Small's (and protagonist David's) embodied experience, transmission depends on the reader's acknowledgement of a relationship through the book - the book operating not as a symbolic site but a discursive-material node for their (partly literal) interconnectedness. Instead of Roland Barthes's metaphorical "umbilical cord" of light connecting body to gaze under a sign of inevitable death, this one connects artist and reader nonphotographically through the multimodal graphic interface of print, ${ }^{37}$ through their joint traces and investments in each other, under the sign of fragile and transient life. This precarious life depends both on the materiality and multimodality of graphic narrative, the distinct way in which it brings together 
the space of reading and the artist's and reader's embodied experiences.

Graphic narrative opens reading to a different kind of attention. Although the potential deepening of hyperattention is first a function of the pace of the alternating rhythm of immersion and travel, it is sustained by the materiality of the narrative object's finitude and tactile weight. In this sense, graphic narrative is a transitional medium equally attuned to the conditions of contemporary convergence culture and to the senses of embodiment, locality, and materiality. As such, graphic narrative fosters a developing sense of the new materiality of the altered spaces of reading and viewing by integrating hyperreading with familiar forms of materiality and, at the same time, demanding deep attention and the refashioning of habits and expectations tied to print and digital textuality. Inhabiting this cultural gutter space, comics have once again - as they have in so many ways before - found a way to flourish in the inbetween.

\section{Notes}

1. Paul McFedries, "P-book," Word Spy: The Word Lover's Guide to New Words, www.wordspy.com/words/p-book.asp

2. Quoted in Douglas Heingartner, "Back Together Again," New York Times, 17 July 2003, www.nytimes.com/2003/07/17/technology/back-together-again.html 3.Ibid.

4.See Art Spiegelman, In the Shadow of No Towers (New York, 2004), hereafter abbreviated I, and David Small, Stitches: A Memoir (New York, 2009), hereafter abbreviated $S$.

5. See James Sosnoski, "Hyper-readers and Their Reading Engines," in Passions, Pedagogies, and 21st Century Technologies, ed. Gail E. Hawisher and Cyn- thia L. Selfe (Logan, Utah, 1999), pp. 161-77.

6. N. Katherine Hayles, How We Think: Digital Media and Contemporary Technogenesis (Chicago, 2012), pp. 61, 62; hereafter abbreviated $H W$.

7. See Armando Petrucci, "Reading to Read: A Future for Reading," in A History of Reading in the West, trans. Lydia G. Cochrane, ed. Guglielmo Cavallo and Roger Chartier (Amherst, Mass., 1999), pp. 345-67.

8. See Thiery Groensteen, "Why Are Comics Still in Search of Cultural Legitimization?" in Comics and Culture: Analytical and Theoretical Approaches to Comics, ed. Anne Magnussen and Hans-Christian Christiansen (Copenhagen, 2000), pp. 29-41; hereafter abbreviated "W."

9. The Francophone tradition with its substantial institutions and scholarly reception from the 1970s has suffered far less from this ambivalence and mutual suspicion between comics and high culture, and the bande dessinée has accordingly survived without any extra emphasis on the book or ties to prestigious literary genre labels.

10. Robert Weiner, "Introduction," in Graphic Novels and Comics in Libraries and Archives: Essays on Readers, Research, History and Cataloging, ed. Weiner (Jefferson, N. C., 2010), pp. 5, 118.

11. Richard Graham, "The Spinner Rack in the Big Red and Ivory Tower: Establishing a Comics and Graphic Novels Collection at the University of Nebraska-Lincoln," in Graphic Novels and Comics in Libraries and Archives, p. 118. This may change once affordable digital comics lending programs are launched in libraries (iVerse Media was launched recently, and others will most likely follow).

12. Roger Sabin, Adult Comics: An Introduction (New York, 1993), p. 93.

13. See Sabin, "The Crisis in Modern American and British Comics, and the Possibilities of the Internet as a Solution," in Comics and Culture, pp. 43-58.

14. Ibid., p. 52.

15. See Benjamin Fredembach, Anne Hillairet de Boisferon, and Edouard Gentaz, "Learning of Arbitrary 
Association between Visual and Auditory Novel Stimuli in Adults: The 'Bond Effect' of Haptic Exploration," PLoS one 4 (Mar. 2009): www.plosone.org/article/info:doi/10.1371/journal.pone.0004844

16. See Florence Bara et al., "The Visuo-Haptic and Haptic Exploration of Letters Increases the Kindergarten-Children's Understanding of the Alphabetic Principle," Cognitive Development 19 July-Sept. 2004): 433-49, lpp.psycho.univ-paris5.fr/pdf/1492.pdf

17. The use of piezoelectric actuators for the output of haptic sensations is the subject of several recent patents and applications; see Louis B. Rosenberg and James R. Riegel, "Haptic Feedback for Touchpads and Other Touch Control," US Patent 8,049,734 B2, filed 15 Nov. 2007, and issued 1 Nov. 2011.

18. Anne Mangen, "Hypertext Fiction Reading: Haptics and Immersion," Journal of Research in Reading 31 (Nov. 2008): 405. For a theoretical critique of

equating the truth of the digital image with the intangible ideality of pure code, see Johanna Drucker, "Digital Ontologies: The Ideality of Form in/and Code Storage or Can Graphesis Challenge Mathesis?" Leonardo 34 (Apr. 2001): 141-45.

19. This disappearance of the unviewed is an important aspect of e-book acceptance more generally. See Jin Gerlach and Peter Buxmann, "Inves- tigating the Acceptance of Electronic Books: The Impact of Haptic Dissonance on Innovation Adoption,” ECIS 2011 Proceedings, aisel.aisnet.org/ ecis2011/141

20. Options include local magnification tools producing enlarged details superimposed on an overview (as in Marvel's online comics reader), zoom- ing in and out (by double-clicking a page on the ComiXology website), or the lack of remediation (the online version of Sarah Ellerton's The Phoenix Requiem-since published in print —offers no dedicated solutions against cropping or for viewing details, putting the layout at the mercy of the user's device).

21. Darren Wershler "Digital Comics, Circulation, and the Importance of Being Eric Sluis," Cinema Journal 50 (Spring 2011): 131. Wershler compares digital reeditions of Marvel Comics's The Fantastic Four on various platforms (DVD and online). Shaped by contingencies of hardware, software, and, most importantly, the screen dimensions relative to the panels and the page, this emerging aesthetic can vary significantly across devices; a comics application for a mobile phone may render the page a mere "organizational concept" to group pictures rather than an image or a space, as Wershel

notes (p. 133). On the other hand, an application optimized for a larger tablet computer and long-form graphic narratives may allow us to "see the full page before we see the panels, and the impact of each panel is therefore exactly as its creator intended" (David Brothers, "Digital December: IDW Launches Digital Graphic Novels on the iTunes App Store [Exclusive]," Comics Alliance, 20 Dec. 2010, comicsalliance.com/idw-digital-graphicnovels-itunes/)

22. See Wershler, "Digital Comics, Circulation, and the Importance of Being Eric Sluis," pp. 133, 131.

23. Brothers, "Digital December"; emphasis added.

24. For a more detailed analysis of the visuality of 9/11 and the Holocaust, see Katalin Orbán, "Trauma and Visuality: Art Spiegelman's Maus and In the Shadow of No Towers," Representations no. 97 (Winter 2007): 57-89.

25. For an alternative view, emphasizing references to the serial and ephemeral over the integrity of the book object, see Hillary Chute, "Temporality and Seriality in Spiegelman's In The Shadow of No Towers," American Periodicals 17 (Autumn 2007): 228-44. In fact, the act of incorporating ephemeral variants and precursors into a single material instantiation is all the more forceful, because it consolidates these elements from sources widely dispersed in space and time (New York, Los Angeles, London, Germany, Italy; between 11 September 2001 and 16 February 2004) rather than from a single regularly published series. While Chute links the effects of traumatic fragmentation in the text to serialized antecedents, I will link them primarily to the multimodality of graphic narrative, the sequences and breaks of which are not identical with those of serialization (the latter arguably not as intact, once incorporated into the book, as she suggests).

26. Aloïs Riegl, Historical Grammar of the Visual Arts, trans. Jacqueline E. Jung (1966; New York, 2004), 
p. 187. Using the term haptic in his earlier work,

Riegl prefers the term tactile sense in this unfinished, posthumously published text. His account of weakening tactility followed the formative period of German research into human haptic perception in the late nineteenth and early twentieth century by Ernst Heinrich Weber, Max von Frey, and Max

Dessoir, which attempted to define the tactile sense and renegotiate its position in the hierarchy of senses, a status that had long wavered between extreme denigration and high esteem. See Human Haptic Perception: Basics and Applications, ed. Martin Grunwald (Boston, 2008), pp. 15-38.

27. Laura E. Tanner, "Holding on to 9/11: The Shifting Grounds of Materiality," PMLA 127 (Jan. 2012): 60, 63-64.

28. See María Lorenzo Hernández, "The Double Sense of Animated Images: A View on the Paradoxes of Animation as a Visual Language," Animation Studies Online Journal 2 (2007), journal.animationstudies.org/category/volume-2/maria-lorenzo-hernandez-the-double-sense-of-animated-

images/

29. Paul Gilroy, "Scales and Eyes: 'Race' Making Difference," in The Eight Technologies of Otherness, ed. Sue Golding (New York, 1997), p. 193.

30. The blankness, however symbolic, always allows for the realistic interpretation of a reflection of strong light. The single exception to spectacle wearing is the mother unbespectacled when she is exposed as a closeted lesbian.

31. Michael Heim, "The Cyberspace Dialectic," in The Digital Dialectic: New Essays on New Media, ed. Peter Lunenfeld (Cambridge, Mass., 1999), p. 32.

32. Groensteen, The System of Comics, trans. Bart Beaty and Nick Nguyen (Jackson, Miss., 2007), pp. 6061.

33. See Benoit Peeters, Case, planche, récit: Lire la bande dessinée (Paris, 1998).

34. David T. Mitchell and Sharon L. Snyder, Narrative Prosthesis: Disability and the Dependencies of Discourse (Ann Arbor, Mich., 2000), p. 48.

35. See Scott St. Pierre, review of Stitches: A Memoir, by Small, Disability Studies Quarterly 31, no. 3 (2011): dsq-sds.org/article/view/1664/1614\%5D

36. Mitchell and Snyder, Narrative Prosthesis, p. 48.

37. Roland Barthes, Camera Lucida: Reflections on Photography, trans. Richard Howard (New York, 1981), p. 81. 


\section{Additional information}

Guide to figures in the publisher version, which had to be omitted here for reasons of copyright.

Figure 1. Art Spiegelman, In the Shadow of No Towers (2005). (P. 2 top row of panels)

Figure 2. David Small, Stitches: AMemoir (2009) (frontispiece)

Figure 3.David Small, Stitches: A Memoir (2009). (p. 175, top 5 panels)

Figure 4. Art Spiegelman, In the Shadow of No Towers (2005). (p. 1 top right corner 10 panels)

Figure 5.David Small, Stitches: A Memoir (2009). (p. 291)

Figure 6. David Small, Stitches: A Memoir (2009). (p. 182, top 2 panels)

Guide to pagination in Critical Inquiry

\begin{tabular}{|l|l|}
\hline Page & begins with \\
\hline 170 & keyword filtering, pecking, \\
\hline 171 & the last varieties of the printed form \\
\hline 172 & the text. Yet, such pulses \\
\hline 173 & each object (even originally identical copies \\
\hline 174 & forms of embodiment not yet fully understood \\
\hline 175 & a more contingent history that does not transcend \\
\hline 176 & revelation of the actual damage \\
\hline 177 & mined (mostly conventional) direction of reading \\
\hline 178 & fragmentation, and dissolution entailed \\
\hline 179 & anything represented corresponds to the insufficiency \\
\hline 180 & does not lead to a restoration of a single \\
\hline 181 & review of Stitches raises questions about the invitation \\
\hline
\end{tabular}

